\title{
Design, evaluation, and implementation of a model-predictive control approach for a force control in friction stir welding processes
}

\author{
Validation of different force-control approaches for friction press joining of aluminum with \\ thermoplastics
}

\author{
Stefan P. Meyer ${ }^{1}\left[\right.$ C . Christian J. Bernauer ${ }^{1} \cdot$ Sophie Grabmann ${ }^{1} \cdot$ Michael F. Zaeh $^{1}$
}

Received: 11 May 2020 / Accepted: 9 June 2020 / Published online: 30 June 2020

(c) The Author(s) 2020

\begin{abstract}
Friction press joining is an innovative joining process for bonding plastics and metals without additives in an overlap configuration. A model-based approach for the design of an axial force controller for friction press joining is presented in this paper. A closed-loop control was set up on the machining center, in which the plunge depth was used as the controlling variable. In order to support the controller development, a nonparametric dynamic process model was developed via a data-based system identification. Subsequently, various control concepts were designed off-line and verified on the actual system. The most promising ones, a proportional controller, a controller created with the pole placement method, and a model predictive controller, were selected for further investigations. The three controllers were re-evaluated and compared by means of a defined input of disturbance variables and reference variables. The model predictive control (MPC) approach as well as the proportional controller were also tested for model uncertainties. For this purpose, different material combinations were joined using the different controllers. Thereby, it was shown that the MPC controller resulted in smaller standard deviations when encountering large model uncertainties. The investigations demonstrated the high potential of friction press joining of plastic components with metals. The results form the basis for future research, whereby the force can be specified as an additional input parameter instead of the plunge depth.
\end{abstract}

Keywords Friction press joining · Polymer-metal joining $\cdot$ Force control $\cdot$ Model predictive control $\cdot$ System identification . Friction stir welding $\cdot$ Friction lap welding

\section{Introduction}

In the Statement of Leipzig 'For the future of aviation' from August 21st, 2019, the German government outlined various fields of action for the civil aviation industry. As one of these focus areas, mass reduction and lightweight design were classified as a competence for Germany for an aviation center [1].

To achieve the ambitious goal of $\mathrm{CO}_{2}$-neutral civil aviation, modern aircraft use lightweight materials and designs such as (fiber-reinforced) plastics and plastic-metal combinations [2]. Particularly the joining of plastics and metals

Stefan P. Meyer

stefan.meyer@iwb.mw.tum.de

1 Boltzmannstr.15, 85748 Garching, Germany without auxiliary parts such as screws or rivets, which introduce additional mass, is challenging. An innovative process that can be used to join plastics with metals without any additional material is friction press joining (FPJ) [3]. With this new method, in particular semi-finished products can be joined with each other, differing FPJ to e.g. assembly injection molding, which is focused on primary forming processes.

In the following, the state of the art for friction press joining will be explained in more detail, and the approaches of the force control for friction stir welding (FSW) processes, which are similar to the FPJ process, will be described in more detail. 


\section{State of the art}

\subsection{Friction press joining}

Friction press joining is a process, which was adapted from friction stir welding, for joining plastics and metals in an overlap configuration without additional materials (see Fig. 1). The advantage of the FPJ-tool, compared to the FSW-tool, is the absence of the pin. This pin is normally used in FSW for the mixing of the material. As this is not necessary in FPJ, the pin can be omitted.

According to Meyer et al. [4], the process consists of five phases. The first upstream step is the surface pretreatment of the bonding area on the metallic joining partner in order to clean the surface and modify the topology and topography (1st phase). The two joining partners (metal and plastic components) are placed in an overlap configuration. A tool, in the default case a cylinder, is then placed onto the joint at a defined rotational speed $n$ (Touch-down phase, 2nd phase). As a result, the tool is rubbed against the metallic surface, causing thermal dissipation, leading to a heat conduction into the joining zone. Here, the plastic joining partner melts and adheres to the metal surface (3rd phase). The two parts are joined by a continuous movement $v$ of the tool over the friction surface (Welding phase, 4th phase). At the end of the process, the tool is retracted in positive $\mathrm{z}$-direction from the metallic surface (Retreat, 5th phase).

Wirth et al. [5] described the process in their article using the example of aluminum EN AW-6082-T6 and polyamide 6 with $15 \%$ glass fiber content (PA6-GF15). The main focus was the investigation of the influence of different laser-based surface pre-treatment methods on the bond strength. Thereby, an increase of $40 \%$ compared to untreated surfaces was achieved with macroscopic pins produced with the Surfi-Sculpt method.

In order to investigate the influence of different process parameters including temperature, contact force, and holding

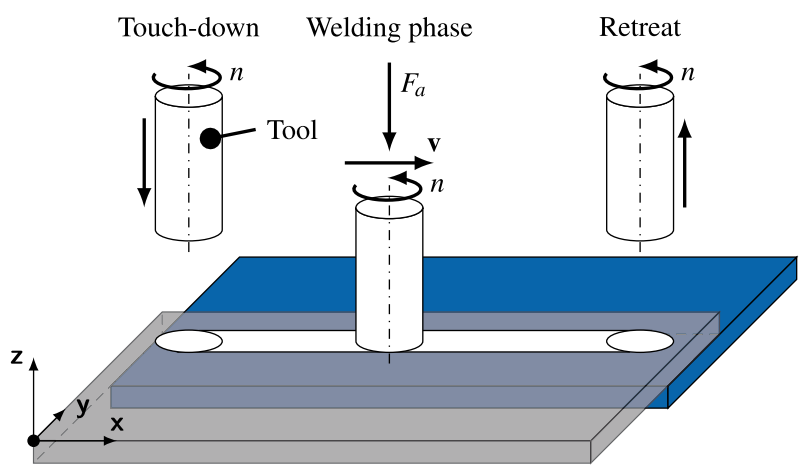

Fig. 1 Schematic process sequence of friction press joining with a thermoplastic material (blue) and a metal (gray) according to [4] time, Wirth et al. [6] used a substitute process based on heat conduction welding. It was proven that the contact force (also named axial force in different investigations as well as in this publication) has a considerable influence on the joint strength. Furthermore, micro-form closure was identified as the main bonding mechanism.

Buffa et al. [7] investigated an FPJ-like process in which the underlying polypropylene, which was melted by an FPJ tool, was extruded through prefabricated holes in the aluminum. This produced a form-fit, resulting in a solid bond. Here, the axial force was determined as a significant process parameter.

Meyer et al. [3] investigated a parameter range for the combination of aluminum EN AW-6082-T6 and polyethylene (PE-HD) for a position-controlled process. In addition, the influence of the contact force was described and a concept for a closed-loop control of the contact force was presented.

Based on these results, Meyer et al. [4] investigated the influence of the process parameters on the resulting temperatures in the friction zone $\left(T_{F}\right)$ and the joining zone $\left(T_{J}\right)$. In addition, it was shown that the contact force $F_{a}$ is not constant due to the position-controlled process and is subjected to high fluctuations $\left(F_{a}=1500-3500 \mathrm{~N}\right)$. However, in the steady state of the process an axial force of around $2000 \mathrm{~N}$ was observed.

In summary, the contact force is an important influencing factor for the FPJ process $[6,7]$ and in position-controlled processes, the resulting force is not constant [4]. For this reason, this paper presents a novel force control system for the FPJ process as announced in [3].

\subsection{Force control in friction stir welding processes}

In the following, the state of the art regarding force control approaches for Friction Stir Welding processes is presented, since this process is similar to FPJ.

Gebhard and Zaeh [8] implemented a force control system on a Heller MCH $250 \mathrm{CNC}$ milling machine, identical to the machine used in the experiments presented in this study (see Sect. 3.2). Here, the axial force $F_{a}$ was calculated via the spindle current $I_{S}$ and adjusted by a proportional controller. This controller was implemented in the G-code of the NC-program. The plunge depth $d_{t}$ was used as a manipulated variable and was adjusted through a synchronized action function of the numeric control. The implementation of the synchronized action in the G-code is described in more detail in Sect. 3.3. However, the relationship between the spindle current and the contact force is not linear and noisy for forces below $5000 \mathrm{~N}$, therefore it is cumbersome to use it for friction press joining $(1500-3500 \mathrm{~N})$ (see Sect. 4.2).

For the robot-based friction stir welding of complex geometries, Soron and Kalaykov [9] developed an approach 
to control the contact force. The force was regulated by adjusting the plunge depth during the process. Since no model was developed for the transfer behavior of the system, a proportional integral controller was designed based on empirical methods.

Longhurst et al. [10] analyzed the rotational speed, the feed rate, and the z-position as manipulated variables. It was shown that by using the rotational speed or the feed rate as a manipulated variable the contact force is subjected to a low standard deviation in comparison to the plunge depth. Nevertheless, a control system by adjusting the plunge depth was regarded as advantageous, since variations in surface conditions of the work piece as well as machine deflections under loading can be compensated. The adjustment of the controllers was based on the Ziegler-Nichols method [11].

$X$. Zhao et al. [12, 13] presented a model-based approach for the design of an axial force control system. First, the influencing factors in the stationary case were investigated. In contrast to Longhurst et al. [10], a limited dependence of the contact force on the rotational speed and the feed rate was detected, which simplifies the model in the stationary case to

$F_{z}=K_{z} d^{\alpha}$

with $K_{z}$ as a gain, $\alpha$ as an adjusting factor, and $d$ as the plunge depth. The adjustment of the factors $K_{z}$ and $d$ was based on the evaluation of the experimental data according to the least squares method (LS method). To derive a dynamic process model, a transfer function with two poles and one zero including the non-linear static correlation was used:

$F_{z}(s)=\frac{b_{1} s+b_{0}}{s^{2}+a_{1} s+a_{0}} e^{-T_{d}} d^{\alpha}(s)$.

The unknown coefficients $a_{0}, a_{1}, b_{0}, b_{1}$, and the delay time $T_{d}$ were calculated from the experimental data using the recursive least squares method. This model was used by the authors for a model-based design of the control system. It was shown that the dynamic approach depicts the behavior of the stationary process accurately.

Oakes and Landers [14] used the results of X. Zhao et al. [12] to design a force control system. One focus was the pre-processing of the noisy measurement data caused by the eccentricity of the tool and the sensor noise. In order to interpret the signal more accurately, a Kalman filter was designed. This improved the control behavior considerably.

Fehrenbacher et al. [15] introduced a simultaneous force and temperature control. The analytic models were parametrized with the System Identification Toolbox from MATLAB. The temperature control (adjusted by the spindle speed) as well as the force control (adjusted by the plunge depth) were designed individually. Subsequently, coupling terms were devised to realize a multi-input-multi-output-system (MIMO-system) using a cross-coupling approach.

Davis et al. [16] presented an observer-based robust control (ARC) for adjusting the contact force with the feed rate as the controlling variable. The contact force was calculated using the spindle power. The authors show that despite the uncertainties in the models, the spindle power contributes to the improvement of the contact force. However, they point out that the power-based calculated force model is still subject to a certain degree of unreliability and should be further improved.

S. Zhao et al. [17] studied the approach of a linear-quadratic controller, also known as Riccati controller, where the feedback matrix is determined by minimizing a quadratic cost function. Based on $[12,14,15]$ a second order system model in the discrete time domain was chosen. However, this controller was only evaluated using one parameter set exemplarily and as a result the general validity cannot be guaranteed.

New approaches in control engineering for non-linear problems include model predictive control (MPC). This approach is based on linear-quadratic regulation (LQR) and requires high computing power to be used in highly dynamic applications $[18,19]$ and for the temperature control in friction stir welding processes [20]. Model predictive controllers are based on the prediction of the system behavior using a mathematical system model. The MPC operates at discrete time intervals, whereby the system behavior is predicted as a function of the input signals for a certain number of time steps up to the prediction horizon $\left(n_{P}\right)$. The manipulated variable is calculated up to a control horizon $\left(n_{C}\right)$. This can correspond to the prediction horizon, but is often chosen shorter due to the dominant influence of the early control signals in order to minimize the required computing power. In each time step, a quadratic optimization problem is solved. The standard cost function consists of four terms, each referring to a specific aspect of the control quality

$J\left(z_{k}\right)=J_{y}\left(z_{k}\right)+J_{u}\left(z_{k}\right)+J_{\Delta u}\left(z_{k}\right)+J_{\epsilon}\left(z_{k}\right)$.

$z_{k}$ refers to the decision made by means of the quadratic program $(\mathrm{QP})$ for the current date $k$ according to

$z_{k}^{T}=\left[u(k \mid k)^{T} u(k \mid k+1)^{T} \ldots u(k+p-1 \mid k)^{T} \epsilon_{k}\right]$

with the determined manipulated variables $u$ and a slip variable $\epsilon_{k}$, which can be used to quantify violations of soft restrictions necessary to solve the QP. The terms of the cost function refer to specific variables, whereby each term contains a weighting factor to be set in the controller design:

- $J_{y}\left(z_{k}\right)$ System deviation

- $J_{u}\left(z_{k}\right)$ Manipulated variable deviations

- $J_{\Delta u}\left(z_{k}\right)$ Change rate of the manipulated variables

- $J_{\epsilon}\left(z_{k}\right)$ Violation of restrictions 
Only the first input element $u(k \mid k)^{T}$ of the determined optimum control signal progression is sent to the controlled system as an input signal. In the next time step, the optimization problem is solved again for the updated system status. This continuous recalculation of the optimum control signal enables the system to respond continuously to unpredictable disturbances.

One of the most important advantages of the MPC is that constraints of the manipulated variables, the controlled variables, and the system conditions can be taken into account in the control algorithm itself. In addition to a linear singleinput-single-output-system (SISO system), an MPC can also be used to control non-linear systems, multi-variable systems, and systems with a dead time. Consequently, this control strategy is a promising approach for friction press joining and will be investigated in more detail hereafter.

Based on the state of the art, it is concluded that the z-position is suitable as a manipulated variable for the control system because it offers a number of advantages. As a result, only this variable will be considered for the model-based controller design in the following. Various control approaches will be simulated and verified on a physical system, whereby the axial force $F_{a}$ is recorded using a dynamometer, filtered, evaluated, and interpreted using a real-time system with a MATLAB Simulink model.

\section{Material and experimental set up}

\subsection{Specimen material}

For the experiments in this paper, two different aluminum alloys were combined with three different plastics. The system model was created using the combinations of aluminum EN AW-6082-T6 with PE-HD to be consistent with the preliminary work of Meyer et al. [3, 4]. The material combinations EN AW-6082-T6 and PA6-GF30 [5, 21] and EN AW-2024-T3 with PPS-CF [22, 23] were used to verify the transferability of the closed-loop control system. Table 1 shows the individual material combinations, their intended uses, and references in the literature. All specimens had dimensions of $250 \times 100 \mathrm{~mm}$ and were arranged in an overlap of $35 \mathrm{~mm}$. The weld length was $200 \mathrm{~mm}$. The

Table 1 Overview of the material combinations used in the individual sections and their references in the literature

\begin{tabular}{llll}
\hline Material combination & & Section & Reference \\
\hline EN AW-6082-T6 & PE-HD & Sect. 4 & {$[3]$ and [4] } \\
EN AW-6082-T6 & PA6-GF30 & Sect. 5.3 & {$[5]$ and [21] } \\
EN AW-2024-T3 & PPS-CF & Sect. 5.3 & {$[22]$ and [23] } \\
\hline
\end{tabular}

thickness varied depending on the material and is indicated in the following.

The aluminum alloy EN AW-6082-T6 is characterized by high corrosion resistance and good formability [24]. This alloy has been investigated in various publications concerning friction press joining [3-6] and serves as the starting point for the design of the control system. The sheet thickness was $t=3 \mathrm{~mm}$.

The aluminum alloy EN AW-2024-T3 is a hardenable, high-strength alloy, which is frequently used in aircraft manufacturing [25]. Its disadvantages are its low corrosion resistance and poor weldability. The sheet thickness was $t=2 \mathrm{~mm}$.

The two aluminum alloys differ in their alloying elements (see Table 2) as well as in their mechanical and thermal properties (see Table 3 ). This allowed an investigation of the transferability of the closed-loop control system to other aluminum alloys. The aluminum joining surfaces were pretreated with a pulsed laser process, based on [4]. However, preliminary investigations showed that the influence of the

Table 2 Percentage of the alloy elements (wt $\%$ ) for the different aluminum alloys according to DIN EN 573-3 [24]

\begin{tabular}{lll}
\hline Element & $\begin{array}{l}\text { EN AW-6082-T6 } \\
\text { in wt\% }\end{array}$ & $\begin{array}{l}\text { EN AW-2024-T3 } \\
\text { in wt\% }\end{array}$ \\
\hline $\mathrm{Si}$ & $0.7-1.3$ & 0.5 \\
$\mathrm{Fe}$ & 0.5 & 0.5 \\
$\mathrm{Cu}$ & 0.1 & $3.8-4.9$ \\
$\mathrm{Mn}$ & $0.4-1.0$ & $0.3-0.9$ \\
$\mathrm{Mg}$ & $0.6-1.2$ & $1.2-1.8$ \\
$\mathrm{Cr}$ & 0.25 & 0.1 \\
$\mathrm{Zn}$ & 0.2 & 0.28 \\
$\mathrm{Ti}$ & 0.1 & 0.15 \\
Other & 0.15 & 0.15 \\
\hline
\end{tabular}

Table 3 Selected thermal and mechanical properties of aluminum EN AW-6082-T6 and EN AW-2024-T3 [26-28]

\begin{tabular}{llll}
\hline Property & Unit & \multicolumn{2}{l}{ EN AW } \\
\cline { 3 - 4 } & & 6082 & 2024 \\
\hline Condition & - & $\mathrm{T} 6$ & $\mathrm{~T} 3$ \\
Tensile strength $R_{m}$ & $\mathrm{~N} \mathrm{~mm}^{-2}$ & $300-350$ & 435 \\
Yield strength $R_{p 0.2}$ & $\mathrm{~N} \mathrm{~mm}^{-2}$ & $240-320$ & 290 \\
Elongation at fracture $A_{50 \mathrm{~mm}}$ & $\%$ & $8-14$ & 14 \\
Young's modulus $E$ & $\mathrm{MPa}$ & 70000 & 70000 \\
Density $\rho$ & $\mathrm{g} \mathrm{cm}^{-3}$ & 2.70 & 2.77 \\
Melting range $T_{m}$ & ${ }^{\circ} \mathrm{C}$ & $585-650$ & $505-640$ \\
Thermal conductivity $\lambda$ & $W^{-1} K^{-1}$ & $150-185$ & $130-150$ \\
Coefficient of linear thermal expan- & $10^{-6} K^{-1}$ & 23.4 & 22.9 \\
$\quad$ sion $\alpha$ & & & \\
\hline
\end{tabular}


surface pretreatment (with the pulsed system) does not have a measurable effect on the process force-only on the adhesion. For this reason, the surface pre-treatment will not be discussed further.

A high density polyethylene (PE-HD) sheet (semi-finished product) supplied by S-Polytec $\mathrm{GmbH}$ was used as one of the plastic joining partners. In addition to a relatively low density, high crystallinity, non-polar character, and good chemical resistance, this group of plastics has a low water absorption capability [29]. For these reasons, these plastics are used in a wide range of applications, from powder materials $[30,31]$ for additive manufacturing to hip implants [32]. The thickness of the material was $t=5 \mathrm{~mm}$.

The second plastic material sheet (semi-finished product) used was a polyamide 6 with 30\% glass fiber content (PA6GF30), which is distributed by Ensinger GmbH under the trade name TECAMID 6 GF30 black [33]. Polyamides are a frequently used material in the field of plastics engineering. They are known for their polar characteristics and high strength, and are the subject of various research projects in the field of joining technology $[34,35]$. The thickness of the material used was $t=5 \mathrm{~mm}$.

The continuous carbon fiber reinforced (wt $43 \%$ ) polyphenylene sulfide (PPS-CF) used is a semi-crystalline highperformance thermoplastic, supplied by TenCate Advanced Composites B.V. under the trade name CFRP Cetex TC1100. The fibers in the laminate are arranged in a $5 \mathrm{H}$ Satin configuration (see Fig. 2) and superimposed in seven layers $[(0 / 90),( \pm 45)]_{3}(0 / 90)$ and consist of 3000 individual fibers per thread. This fiber-matrix composite is characterized by a very high heat distortion temperature (HDT), high chemical

Fig. 2 Schematic drawing of the 5H Satin structure, showing the warp and fill direction. The non-transparent yarns consist of the repetitive unit cells (based on [39])

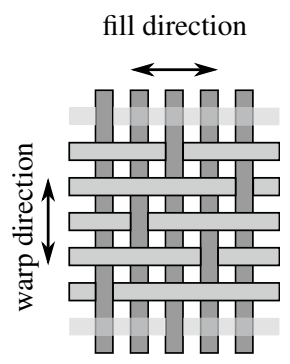

resistance, and high stiffness, which make it a widely used material in the aerospace sector [36] and research [37]. PPS can be produced as a crosslinkable thermoset or as a thermoplastic, however the latter has by far the greater significance and was used for the present publication. The material thickness is derived by the mentioned layer set up and is $2.17 \mathrm{~mm}$ [38].

The three thermoplastics used are typical representatives of commodity, engineering, and high-performance plastics, and are used in an unreinforced condition (PE-HD), with short glass fibers (PA6-GF30), and as endless fiber reinforced laminate (PPS-CF). This selection ensured that the results obtained can be validated over a wide spectrum of material combinations (see Table 4). The particular combinations of aluminum and plastic (see Table 1) are both the subject of current research and of commercial interest.

\subsection{Welding system and clamping}

The experiments were conducted on a Heller MCH 250 CNC milling machine as in [4]. The spindle is positioned horizontally and can be moved in the $\mathrm{x}$ - and $\mathrm{y}$-direction. The tilt angle is adjusted by rotating the clamping base around the $\mathrm{b}$-axis. The clamping base can be moved in the z-direction and provides a maximum force of $30 \mathrm{kN}$ with a positioning accuracy of $0.001 \mathrm{~mm}$. The machine is equipped with a Sinumerik 840D sl control system. More detailed information on the control technology is given in Sect. 3.3.

The samples were clamped using a customized clamping system made of C45 steel with a base thickness of $35 \mathrm{~mm}$ (see Fig. 3). Due to this solid design, the deformation of the clamping system can be neglected in relation to the specimen material.

For the tests, two cylindrical tools made of XCrMoV5 with a diameter of $25 \mathrm{~mm}$ were designed and fabricated. Tool 1 has a profiled front face (see Fig. 4b). Tool 2 has a flat front face (see Fig. 4c). Both have been designed to be clamped into a Weldon mount. By using the two tools, the transferability of the designed control system to other tool geometries can be analyzed in Sect 5.3.
Table 4 Selected mechanical and thermal properties of the plastics used [29, 33, 38]

\begin{tabular}{lllll}
\hline Property & Unit & PE-HD & PA6-GF30 & PPS-CF \\
\hline Tensile strength $R_{m}$ & $\mathrm{~N} \mathrm{~mm}^{-2}$ & 23 & 98 & $752-785$ \\
Yield strength $R_{p 0.2}$ & $\mathrm{~N} \mathrm{~mm}^{-2}$ & - & 98 & 608 \\
Elongation at fracture $A$ & $\%$ & - & 5 & - \\
Young's modulus $E$ & $\mathrm{MPa}$ & 1100 & 5700 & $56000-58000$ \\
Density $\rho$ & $\mathrm{g} \mathrm{cm}^{-3}$ & 0.96 & 1.36 & 1.55 \\
Crystallization temperature (range) $T_{c}$ & ${ }^{\circ} \mathrm{C}$ & $126-130$ & 218 & 280 \\
Thermal conductivity $\lambda$ & $\mathrm{Wm}^{-1} K^{-1}$ & 0.38 & 0.41 & - \\
Coefficient of linear thermal expansion $\alpha$ & $10^{-4} K^{-1}$ & 1.8 & 0.6 & - \\
\hline
\end{tabular}




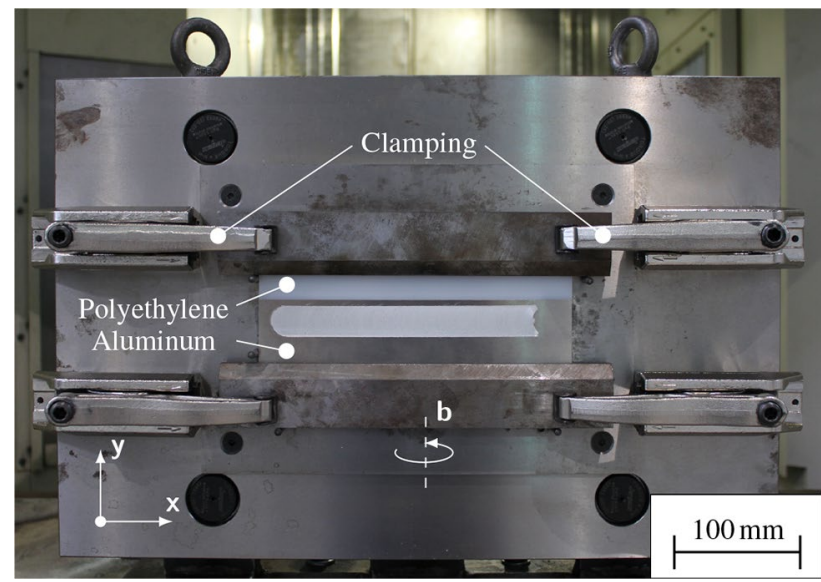

Fig. 3 Clamping system for joining aluminum and polyethylene by friction press joining with a clamped sample after the joining process

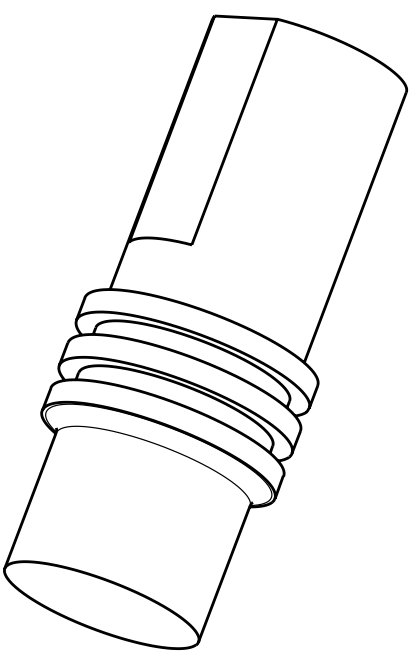

(a) Tool

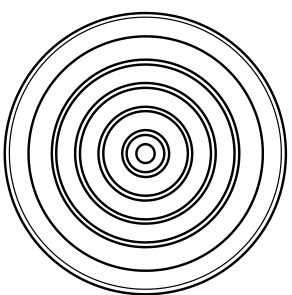

(b) Tool 1

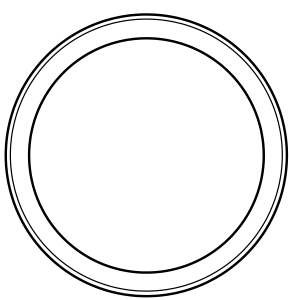

(c) Tool 2
Fig. 4 Comparison of the two tools used for this research (a) with top view of the profiled friction surface (b) and top view of the flat friction surface (c)

\subsection{Force control system}

Three components are of decisive importance for the implementation of the force control: a dynamometer to measure the force, a programmable real-time computer to determine the manipulated variable, and an interface for adapting the z-position of the clamping base (see Fig. 5).

The contact force $F_{a}$ was measured using a sensor unit (dynamometer), which was integrated between the Weldon adapter for the FPJ tool and the SK50 adapter of the spindle. This device can also be used to measure the corresponding torque $M_{a}$. However, this variable will not be considered in the further discussion. The signal as well as the power were

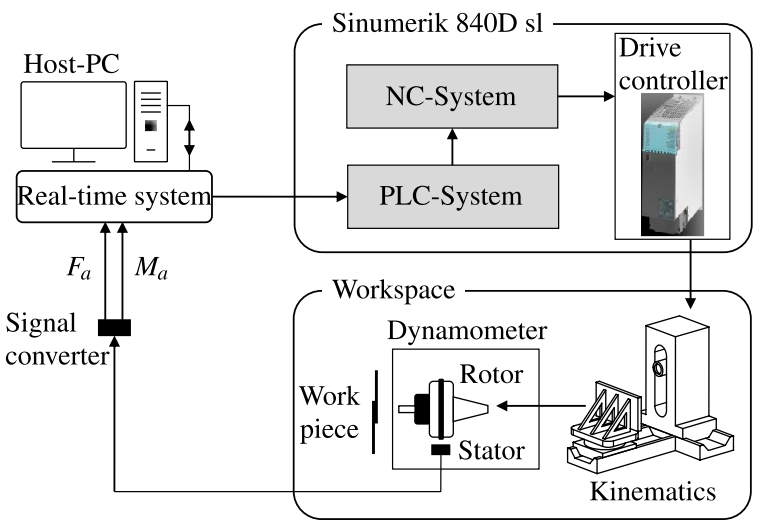

Fig. 5 A schematic illustration of the system architecture for the implementation of the force control on a Heller MCH 250

wirelessly transmitted via induction. The measurement data were sent from the rotating sensor unit (rotor) to a receiver (stator) mounted in the working chamber. The sampling frequency was $9600 \mathrm{~Hz}$.

The dSpace MicroLabBox real-time computer provided the software logic for the entire signal processing (outside of the machining center), including the controller. This realtime computer is connected via Ethernet to a host $\mathrm{PC}$ where control parameters can be set via a graphical user interface, developed with the program ControlDesk. The sample rate of this system was $10 \mathrm{kHz}$. The signal processing logic was designed using MATLAB Simulink (R2017a), converted into a $\mathrm{C}$ code and transferred to the real-time computer, that transmitted an analog control signal to the PLC-System.

The analog control signal was processed by an analog-todigital converter (Simatic S7-300 analog module SM334) at the machining center and converted proportionally into a numerical value ranging from 0 to 100 in the programmable logic controller (PLC). This numerical value can be imported into the numerical control (NC) program as a variable. The sampling frequency was in a range of 5-30 Hz. However, the precise value is not decisive for the controller design, therefore an average value of $17.5 \mathrm{~Hz}$ is assumed in the following.

The adaptation of the z-position was implemented by a superposition of the path trajectory (friction trajectory) using a synchronized action implemented in the NC code. This synchronized action superimposes the programmed path curve continously and can therefore be used to adjust the path profile. The axis settings have been defined as integrating, which means that the individual values per cycle accumulate. The minimum step of the infeed was set to $0.001 \mathrm{~mm}$ (limited by the positioning accuracy of the machining center). At an interpolation rate (IPO-rate) of 167 $\mathrm{Hz}$, the infeed speed was $0.167 \mathrm{~mm} \mathrm{~s}^{-1}$. 
A summary of the clock frequencies that are important for the development of the control system is given in Table 5 .

\section{Design of a force control system for friction press joining}

\subsection{Filter design}

Since the force signal, emitted by the dynamometer, contains significant noise, which is normally distributed and can be described as additive white Gaussian noise (AWGN) (see Fig. 6), it is necessary to filter the signal before further processing. Following [10] and [12], a time domain moving average filter with a window width $n_{M A}$ of 500 points was used. In contrast to [10] (sampling frequency of $3.33 \mathrm{~Hz}$ ) and [12] (sampling frequency of $10 \mathrm{~Hz}$ ) which allowed a window width of 5 points, a sampling frequency of $10 \mathrm{kHz}$ could be realized due to the high computing power of the system technology used. This resulted in a signal delay $\tau_{M A}$ of $0.025 \mathrm{~s}$ according the used 500 sample points and the used frequency $f$ of $10 \mathrm{kHz}$, calculated with:

$\tau_{M A}=\frac{f *\left(n_{M A}-1\right)}{2}$.

The combination of the high resolution and the selected window width led to a significant noise reduction (see Fig. 7). At the same time, this filtered signal permits the evaluation of a single spindle rotation in the process (see Fig. 15). Therefore, this pre-filtering method, with 500 sample points at a sampling rate of $10 \mathrm{kHz}$, was used for the measurements of the force signal described in the following.

\subsection{Non-force controlled process}

As previously mentioned in the section of the state of the art, unregulated processes are subject to large fluctuations in the force profile. In addition, the control according to [8], which represents a simple proportional control, is not suitable for the force range of the FPJ process (see Fig. 8). Although a constant force level is maintained here, the target value of

Table 5 Clock frequencies of the related system components for the closed-loop control

\begin{tabular}{ll}
\hline Part & Frequency \\
\hline Dynamometer & $9600 \mathrm{~Hz}$ \\
Real-time computer & $10 \mathrm{kHz}$ \\
Internal position controller Heller MCH 250 & $500 \mathrm{~Hz}$ \\
IPO Heller MCH 250 & $167 \mathrm{~Hz}$ \\
AD-converter & $5 \mathrm{~Hz}$ to $30 \mathrm{~Hz}$ \\
\hline
\end{tabular}

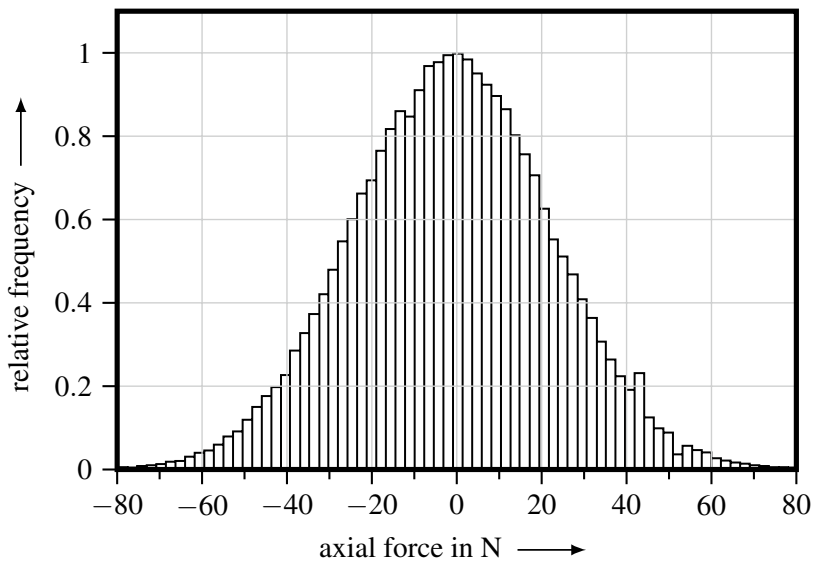

Fig. 6 Normalized histogram of the force signal of an unloaded (no contact to the workpiece) spindle, caused by the noise of the sensor itself at a rotational speed $n$ of $400 \mathrm{~min}^{-1}$ over $20 \mathrm{~s}$

$2000 \mathrm{~N}$ is clearly missed. A simple adjustment by means of a correction factor would reduce this effect. However, this does not allow for more complex control structures due to the implementation of the controller in the NC code. This can limit the achievable dynamics of the closed-loop system.

\subsection{System identification and modeling}

As reported in the section on the state of the art, a modelbased design of the closed-loop controller is advantageous [12]. For this purpose, the first step included the mathematical modeling of a system that describes the dynamic relationship between the manipulated variable (plunge depth $E_{t}$ ) and the output variable (axial force $F_{a}$ ). A gray box method was used to describe the correlation.

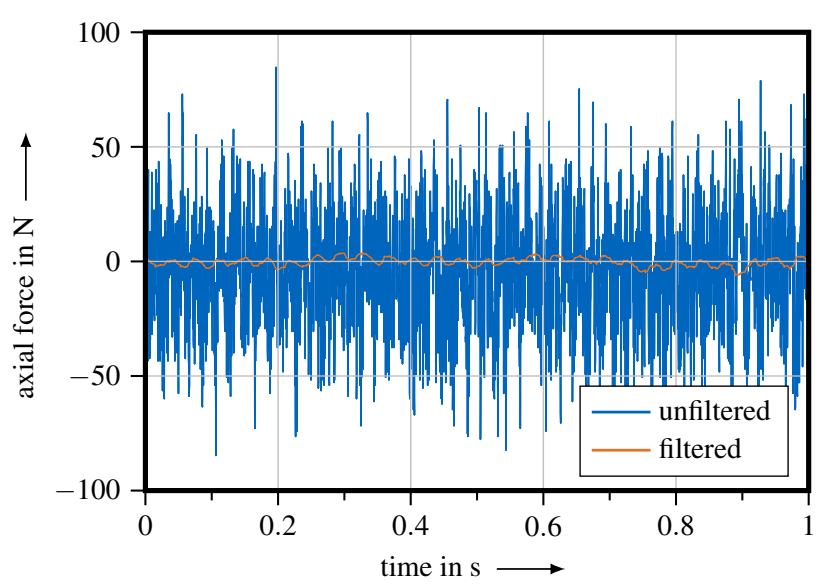

Fig. 7 Comparison of the unfiltered force signal (blue) with the force signal processed with a moving average filter (orange) over $1 \mathrm{~s}$ for an unloaded spindle with a rotational speed $n$ of $400 \mathrm{~min}^{-1}$ 


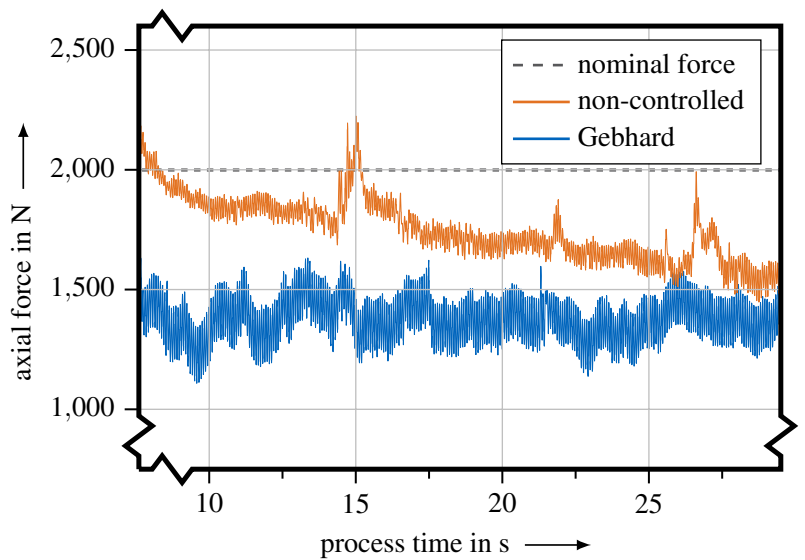

Fig. 8 Comparison of a non-controlled process and a controlled process according to [8] for the material combination EN AW-6082-T6 and PE-HD with $n=800 \mathrm{~min}^{-1}$ and $v=450 \mathrm{~mm} \mathrm{~min}^{-1}$ at a nominal force of $F_{a, \text { nom }}=2000 \mathrm{~N}$

Table 6 Parameter sets (PS) for the system identification with a tilt angle $\alpha$ of $1^{\circ}$

\begin{tabular}{llll}
\hline $\begin{array}{l}\text { Parameter } \\
\text { Set }\end{array}$ & $\begin{array}{l}\text { Rotational speed } n \\
\text { in min }\end{array}$ & $\begin{array}{l}\text { Feed Rate } v \\
\text { in mm min }\end{array}$ & $\begin{array}{l}n / v \text { Ratio } \\
\text { in } \mathrm{mm}^{-1}\end{array}$ \\
\hline PS1 & 400 & 150 & 2.67 \\
PS2 & 600 & 600 & 1.00 \\
PS3 & 800 & 300 & 2.67 \\
PS4 & 800 & 450 & 1.78 \\
PS5 & 1000 & 750 & 1.33 \\
\hline
\end{tabular}

For the excitation of the system, joining processes were conducted with five parameter sets (PS1-PS5) to obtain five individual models (M1-M5), whereby the plunge depth was changed stepwise from $0.15 \mathrm{~mm}$ initially to $0.20 \mathrm{~mm}$ at $x_{1}=80 \mathrm{~mm}$ and $0.25 \mathrm{~mm}$ at $x_{2}=140 \mathrm{~mm}$.

In accordance with [3], five parameter sets were selected which both represent a large spectrum of the parameter space and provide high bond strength. These parameter sets are given in Table 6 .

The first step at $x_{1}=80 \mathrm{~mm}$ corresponds to the area from where a steady state can be expected (in accordance to [4]).

To ensure the change of the plunge depth $\Delta z$ of $0.05 \mathrm{~mm}$, the maximum offset value of $0.001 \mathrm{~mm}$ (see Sect. 3.3) per cycle must be added 50 times to the programmed trajectory. Since the sample time of the interpolator (IPO) is $6 \mathrm{~ms}$, the $\mathrm{z}$-axis of the machining center requires $300 \mathrm{~ms}$ to execute the change in the z-position. During the joining process, the axial force $F_{a}$ was recorded.

In order to avoid irregularities during the touch-down phase and the withdrawal of the tool for the system identification, the determined test data were uniformly trimmed. In this way, the data from the first $60 \mathrm{~mm}$ and the last $10 \mathrm{~mm}$ were removed.

The adjusted data showed no global integrating behavior (see Fig. 9). Although the axial force rises suddenly to a high level as soon as the plunge depth is increased, this force peak decreases shortly thereafter in the area of the constant plunge depth. Here, the previous force level is restored. This effect is also known from the FSW process and is described as a self-regulating process [40]. This effect results in the controlled system being regarded as a self-regulating system.

To mathematically describe the system, the MATLAB System Identification Toolbox was used in combination

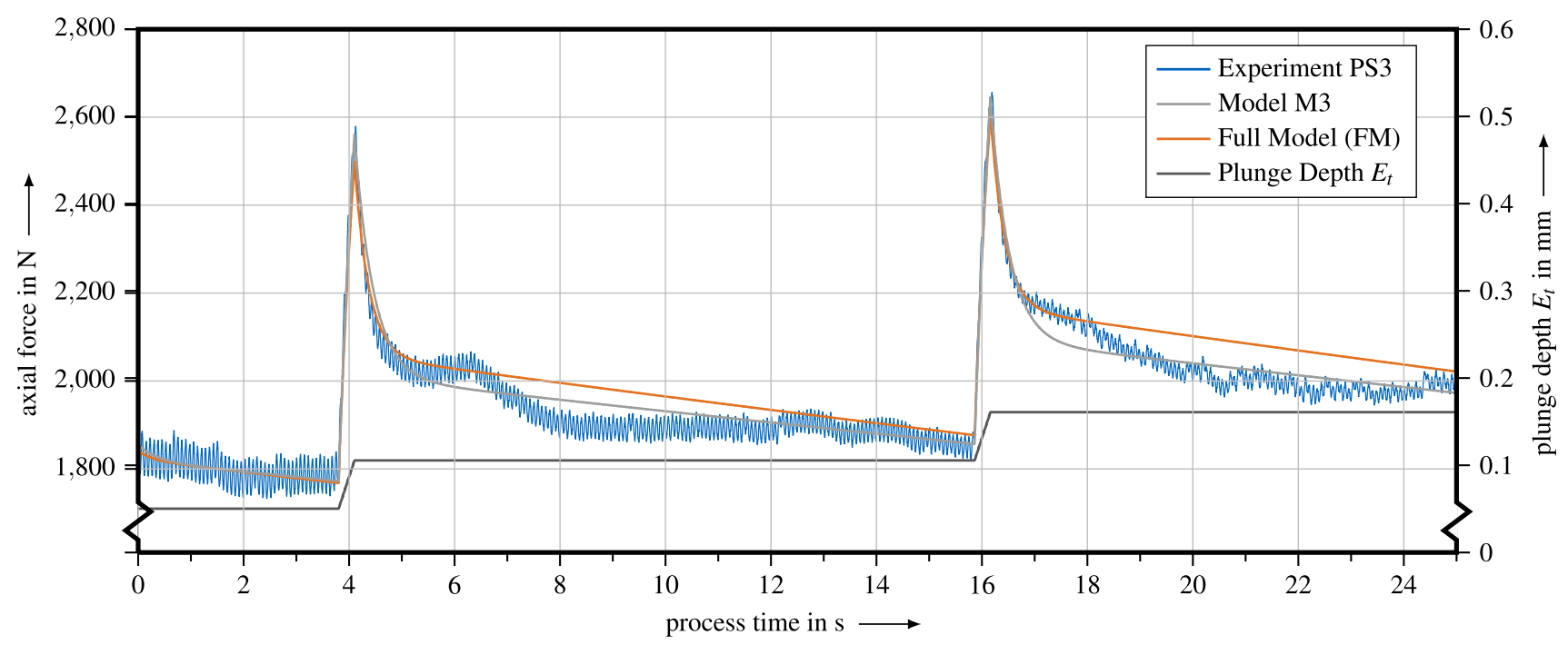

Fig. 9 Comparison of the step response $\left(F_{a}\right)$ based on the experiment PS3 (blue), the resulting model (M3), the averaged system model (FM) and the excitation via the changing plunge depth $E_{t}$ 
with the trimmed data. The model structure was based on a second order transfer function with one zero (LTI system).

The delay time $T_{d}$ was determined by the superposition of the input and output variables $(0.128 \mathrm{~s})$. Then, a transfer function was determined for each parameter set (PS1-PS5). The Normalized Root Mean Squared Error (NRMSE) $\kappa_{f i t}$ was used as a quality indicator for the individual transfer functions. This error is calculated from the measurement and simulation data:

$\kappa_{f i t}=100\left(1-\frac{\left\|y_{\text {mea }}-y_{\text {model }}\right\|}{\left\|y_{\text {mea }}-\overline{y_{\text {mea }}}\right\|}\right)$,

where $y_{\text {mea }}$ is the data vector measured at the output, $\overline{y_{\text {mea }}}$ represents the mean value of the measured data and $y_{\text {model }}$ the simulated data vector. A value of $100 \%$ corresponds to an exact match, while $0 \%$ would correspond to a match with a horizontal line. The degree of congruence also depends on the oscillations occurring in the force signal (see Fig. 15), since these cannot be modeled with a second order transfer function. However, since these oscillations were caused by the eccentricity of the tool (see Sect. 5.4), they do not have to be further considered for the system modeling.

Based on [12] and [14], the determined coefficients of the individual transfer functions were averaged in order to obtain the coefficients for the full model (FM) in the parameter range considered (see Table 7).

The system model in the continuous time domain is given by the transfer function $G(s)$ :

Table 7 Coefficients of the single transfer functions PS1-PS5 as well as the calculated coefficients of the full model (FM) with the corresponding NRMSE

\begin{tabular}{llllll}
\hline Parameter Set & $a 1$ & $a 2$ & $b 1$ & $b 2$ & $\kappa_{\text {fit }}$ \\
\hline PS1 & 2.679 & 0.00832 & 6393 & 1686 & $48.33 \%$ \\
PS2 & 4.262 & 0.03473 & 5674 & 7350 & $26.25 \%$ \\
PS3 & 2.805 & 0.01878 & 7065 & 4542 & $74.86 \%$ \\
PS4 & 4.209 & 0.02024 & 6489 & 8395 & $62.80 \%$ \\
PS5 & 4.609 & 0.06285 & 8659 & 14670 & $67.96 \%$ \\
FM & 3.7128 & 0.0290 & 6856 & 7329 & - \\
\hline
\end{tabular}

$G(s)=\frac{F_{a}(s)}{U(s)}=\frac{6856 s+7329}{s^{2}+3.7128 s+0.0290} e^{-0.128 s}$

Since both of the poles are in the left complex half-plane at $s_{1}=-0.0078$ and $s_{2}=-3.7050$, the system can be considered as stable. This result is also confirmed by the decreasing impulse responses (see Fig. 9). The transfer function has a zero at $s_{01}=-1.069$. This system model was used in the following for the model-based controller design.

\subsection{Model-based controller design}

With the aid of the system model (see Fig. 10), the closedloop system behavior could be investigated through simulations. In these simulations, the existing manipulated variable limitations were taken into account and known disturbances were mapped. A Gaussian distributed noise with a standard deviation corresponding to the filtered force signal and a sinusoidal oscillation with an amplitude of $50 \mathrm{~N}$, and a frequency of $83.78 \mathrm{rad} \mathrm{s}^{-1}$ (this corresponds to a rotational speed of $800 \mathrm{~min}^{-1}$ ) simulating the tool's run-out were additively superimposed on the controlled system output. The simulation time $t_{\text {sim }}$ was $25 \mathrm{~s}$ in each case, whereby the simulated nominal force $F_{a, n o m}$ from initially $1800 \mathrm{~N}$ was set to $2300 \mathrm{~N}$ after $12.5 \mathrm{~s} . F_{a_{\text {res }}}$ corresponded to the resulting simulated force, $F_{a, s i m}$ to the simulated force superimposed with the noise, and $e(t)$ corresponded to the force error between the nominal and the actual force. Through this simulation, different control concepts were designed and compared.

\subsubsection{Ziegler-Nichols method}

A common and widespread method for designing P and PI controllers is the Ziegler-Nichols method. An constant increase of the gain could be achieved by a superimposed ramp function multiplied by the gain. This method was simulated and experimentally emulated and was used to validate the system model again. The determined critical values $\left(K_{\text {crit }}\right.$ and $T_{c r i t}$ ), control parameters for the P and PI controller, and the deviations between simulation and experiment are given in Table 8. Figure 11 shows the simulated and the actual system behavior for a given control gain value. In the following,

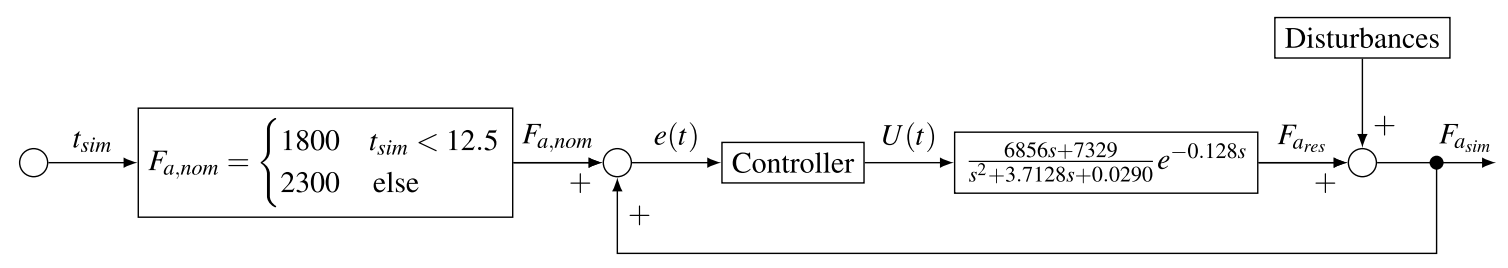

Fig. 10 Layout of the simulation model for the design of the controllers with an integrated nominal force step after $12.5 \mathrm{~s}$ 
Table 8 Simulatively and experimentally derived values for the $\mathrm{P}$ and the PI controller according to the method of Ziegler and Nichols

\begin{tabular}{llll}
\hline Parameter & Simulation & Experiment & Deviation \\
\hline$K_{\text {crit }}$ & 0.00207 & 0.0022 & $6 \%$ \\
$T_{\text {crit }}$ & 0.455 & 0.446 & $2 \%$ \\
$K_{P}$ & 0.00104 & 0.0011 & $6 \%$ \\
$K_{P, P I}$ & 0.00093 & 0.00099 & $6 \%$ \\
$T_{I}$ & 0.38675 & 0.3791 & $2 \%$ \\
\hline
\end{tabular}

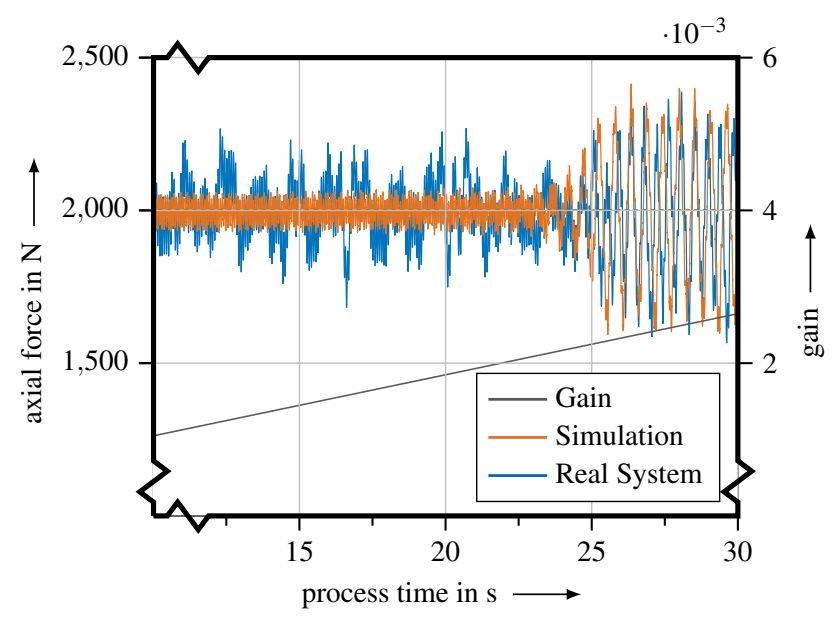

Fig. 11 Comparison of the real and simulated force profile with a changing gain factor over a weld with a constant feed rate of $450 \mathrm{~mm}$ $\mathrm{min}^{-1}$ and a rotational speed of $800 \mathrm{~min}^{-1}$

the controllers designed with the Ziegler-Nichols method are labeled $P_{Z N}$ and $P I_{Z N}$.

\subsubsection{Model-based proportional controller}

Due to the selected set up with the integrating synchronized action, a sufficient stationary accuracy could be achieved by a pure proportional control. In this example, the controller gain $(K(s)=0.00114)$ was designed purely simulatively (in contrast to $P_{Z N}$ ) with the system model developed in Sect. 4.3. The objective was to avoid any overshoot with a simultaneously low settling time.

The proportional controller designed via simulation is named $P_{\text {Model }}$ in the following.

\subsubsection{Compensation controller}

In order to compensate the steady-state error of the proportional controller, a more complex control structure in the form of a compensation controller was developed. This control structure consists of two parts: the reciprocal transfer function of the controlled system and a component that determines the resulting open-loop transfer function. The reciprocal transfer function compensates all zeros and poles of the open-loop, so that the transfer behavior is characterized only by the second control element.

The following open-loop transfer behavior $G_{0}(s)$ was defined by:

$G_{0}(s)=G(s) K(s)$

$=G(s) * \frac{0.0005(s+3.705)(s+0.0078)}{s(s+1.069)}$

$=\frac{3.428}{s} e^{-0.128 s}$,

with $G(s)$ as the transfer function of the controlled system (see Eq. 7) and $K(s)$ as the transfer function of the controller. Hereafter, the controller is referred in the text as $P_{C o m p}$.

\subsubsection{Model predictive control}

As shown in the section on the state of the art, the model predictive control is a promising approach to regulate a process, assuming that sufficient computing power is available to calculate the cost function in each time step. In general, there are three important controller settings, which must be taken into account:

- Sample time $t_{S}$

- Prediction horizon $n_{P}$

- Control horizon $n_{C}$

In addition to these settings, hard and soft constrains can be set. Due to the limitation of the analog output of the realtime computer $(0-10 \mathrm{~V})$, this limit was defined as a hard constraint. This means that this limit can never be exceeded, which is also specified in the internal model of the MPC.

The MPC system model used for the design of the MPC was described in Eq. 7. The sample time $t_{s}$ was set to $0.064 \mathrm{~s}$. This value depends on the available computing power and on the dynamic requirements of the system. Lower sample times would lead to a higher frequency of changes in the output signal. The selected clock rate corresponds to a frequency of approximately $15 \mathrm{~Hz}$ which can still be processed by the integrated system elements in the Heller MCH 250.

The prediction horizon $n_{P}$ is calculated from the reaction time of the system, i.e., the settling time (approximately $0.6 \mathrm{~s}$ ) divided by the control interval $t_{S}$, and is therefore 10. The control horizon $n_{c}$ was set at $30 \%$ of the prediction horizon to, which is 3 in this case.

In the following, the MPC controller is labeled as $P_{M P C}$, whereby all control concepts, regardless of their design, are referred to as $P$ in this paper, even if they are not proportional controllers. 


\section{Experimental analysis and discussion of the closed loop approach}

\subsection{Analysis of the stationary behavior}

The five designed controllers $\left(P_{Z N}, P I_{Z N}, P_{\text {Model }}, P_{C o m p}\right.$, and $P_{M P C}$ ) were initially tested for their steady-state accuracy. For that purpose, tests were conducted with a parameter setting $\left(n=800 \mathrm{~min}^{-1}\right.$ and $\left.v=450 \mathrm{~mm} \mathrm{~min}^{-1}\right)$ at a tilt angle of $1^{\circ}$ and an initial plunge depth of $0.1 \mathrm{~mm}$ of the tool center. To measure the steady-state accuracy, and to avoid the touch-down and the retreat phase in the measurement data, the first $20 \mathrm{~mm}$ and the last $10 \mathrm{~mm}$ of the trajectory were not considered. The mean value of the measured axial force $\left(\bar{F}_{a}\right)$ and the standard deviation $\sigma$ were then determined over the seam length (see Table 9). The objective was to receive the smallest possible stationary deviation with a minimum variation of the contact pressure $\left(\sigma_{\text {target }}=0\right)$.

The results show that when using the $P I_{Z N}$ controller the mean force is near the target value $\left(\Delta F_{a}=0.7 \mathrm{~N}\right)$, although the signal has a high standard deviation. One explanation is the integrating element of the controller, as well as the high static amplification of the controlled system. The zeros of the open-loop denominator polynomial are approximately in the origin, which leads to a double integrating behavior of the system. This characteristic increases the control error almost quadratically, which leads to a more unsteady force profile and thus to higher standard deviations.

In contrast, the basic controller $P_{Z N}$ results in a lower standard deviation of the force signal. The otherwise typical permanent control deviation is compensated by the mentioned integrating element in the system.

The controller $P_{\text {Model }}$ has similar standard deviations and average values as the controllers with an internal system model. In addition, this designed proportional controller is preferable over the controller based on Ziegler-Nichols.

Table 9 A comparison of the different controllers in terms of the steady-state accuracy for the given parameter set

\begin{tabular}{llll}
\hline Controller & Mean Value $\bar{F}_{a}$ & $\begin{array}{l}\text { Standard Devia- } \\
\text { tion } \sigma \\
\text { in N }\end{array}$ & $\sigma / \bar{F}_{a}$ \\
& in N & 83.7 & in \% \\
\hline$P_{Z N}$ & 1994.0 & 155.6 & 4.20 \\
$P I_{Z N}$ & 2000.7 & 81.6 & 7.78 \\
$P_{\text {Model }}$ & 2001.6 & 74.1 & 4.08 \\
$P_{\text {Comp }}$ & 1994.4 & 80.3 & 3.71 \\
$P_{M P C}$ & 2007.3 & & 4.00 \\
\hline
\end{tabular}

The controllers with internal system model $\left(P_{\text {Comp }}\right.$ and $\left.P_{M P C}\right)$ have the smallest standard deviation in the force signal. This low standard deviation is essential for precise force adjustment.

Due to these reasons, the controllers $P_{\text {Model }}, P_{\text {Comp }}$, and $P_{M P C}$ were selected for further analysis.

\subsection{Analysis of the dynamic behavior}

In order to evaluate the dynamic performance of the three selected controllers, a nominal force step $F_{a, \text { nom }}$ from 1800 to $2300 \mathrm{~N}$ was introduced during welding, analogous to the simulations before. The set point step change was executed in the middle of the trajectory. The standard deviations of the step response of the individual controllers were subsequently determined (see Table 10).

The dynamic analysis shows that both the $P_{M P C}$ and the $P_{\text {Model }}$ have lower standard deviations, although the compensation controller is within this range. However, the compensation controller $P_{C o m p}$ has an integrated I-component that has to be reset during the plunge phase and dwell time. This means that the plunge motion and dwell time cannot be force controlled with this controller set up without adding additional features. Thus, the following section focuses on the $P_{M P C}$ controller as a representative of the model-integrated controllers and $P_{\text {Modell }}$ as a simple proportional controller.

For a further investigation regarding the closed-loop behavior of the system, experiments with defined disturbance and command variables were conducted on the basis of $[10,14,15]$. For this purpose, an application as a followup control was examined in a first study. Therefore, a triangular signal with a frequency of $0.05 \mathrm{~Hz}$ and a peak-tovalley value of $1000 \mathrm{~N}$ was superimposed on the force set point of $2000 \mathrm{~N}$ (see Fig. 12). Subsequently, the standard deviations of the difference between the command signal and the measured force signal were compared. This resulted in a standard deviation for $P_{\text {Model }}$ of $96.4 \mathrm{~N}$ and for $P_{M P C}$ of $79.2 \mathrm{~N}$. The results show that the use of the designed model predictive controller offers advantages for follow-up control.

In order to introduce defined disturbances, grooves of $70 \mathrm{~mm}$ length and a depth of $0.2 \mathrm{~mm}$ and $0.4 \mathrm{~mm}$, respectively were machined into the metallic joining partner. This results in two physical steps on the aluminum plate $\left(x_{1}=70 \mathrm{~mm}\right.$ and $\left.x_{2}=140 \mathrm{~mm}\right)$ at which the controller has

Table 10 A comparison of the different controllers in terms of the dynamic behavior at the nominal setpoint step change

\begin{tabular}{ll}
\hline Controller & $\begin{array}{l}\text { Standard } \\
\text { deviation } \\
\sigma \text { in N }\end{array}$ \\
\hline$P_{\text {Model }}$ & 89.2 \\
$P_{\text {Comp }}$ & 96.1 \\
$P_{M P C}$ & 91.6 \\
\hline
\end{tabular}




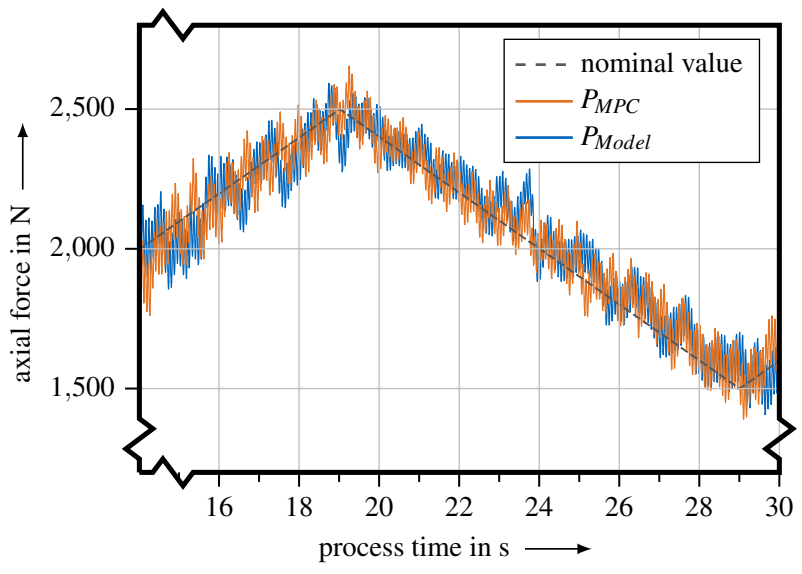

Fig. 12 A section of the given nominal triangular force and the corresponding force signals of the two considered control concepts for the validation of the closed-loop control concepts as a follow-up control

to intervene with a change of the plunge depth to keep the contact force constant (see Fig. 13). Next, the mean force values and standard deviations of the test data were evaluated (see Table 11).

The data showed values in a similar range. The model predictive control tended to provide more accurate mean values of the force, while the proportional controller showed lower standard deviations.

Based on the experiments conducted, both control concepts can be considered as sufficiently accurate and stable for the material combination EN AW-6082-T6 and PE-HD in the stationary state and during the dynamic behavior. In addition, they can well deal with disturbances such as setpoint changes or physical steps. Next, model uncertainties have to be studied in order to test the transferability of the controllers to other material combinations or operating point shifts.

\subsection{Transferability of the results}

To test the behavior of the controllers when encountering model uncertainties, other parameter settings were tested before the material combination was changed.

The evaluation concerning the change of the parameters feed rate and rotational speed showed that the model predictive approach has slight advantages regarding the mean force value and the standard deviation (see Table 12). In addition, it was shown that the feed rate has a decisive influence on the standard deviation. It can be concluded, that a smaller feed rate leads to a lower standard deviation, and thus to a higher accuracy of the control system.

In order to introduce model uncertainties as well as to verify the transferability to other material combinations, the plastic joining partners were replaced by PA6-GF30 in the first step as described in Table 1. For the experiments

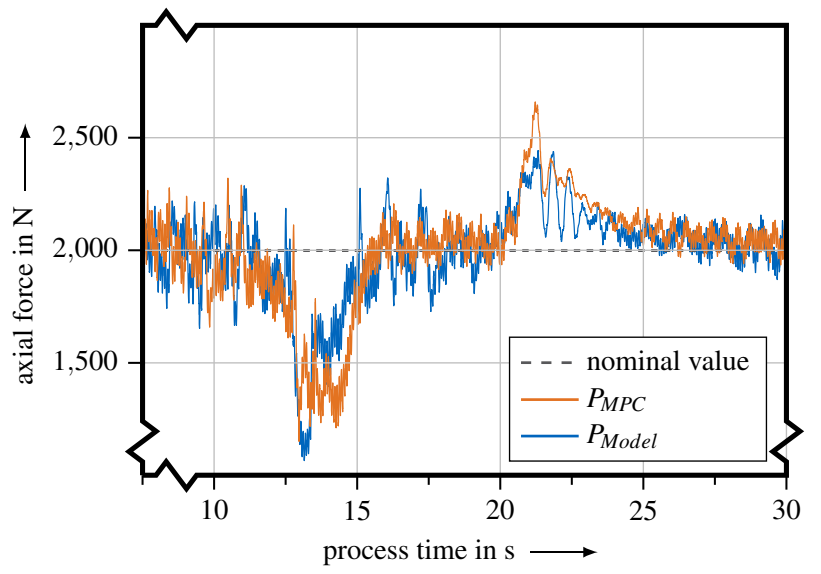

(a) Force curve

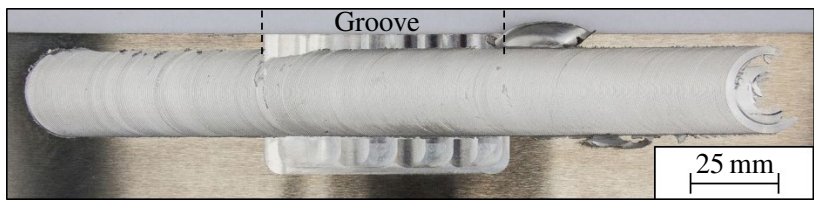

(b) Surface of the sample

Fig. 13 13a) Comparison of the force curves when joining a specimen with an integrated groove in the aluminum of $0.4 \mathrm{~mm}$ in depth $\left(n=800 \mathrm{~min}^{-1}, v=450 \mathrm{~mm} \mathrm{~min}^{-1}\right.$ and $\left.F_{a, n o m}=2000 \mathrm{~N}\right)$ and $\left.13 \mathrm{~b}\right)$ the image of a corresponding specimen (top-view) $\left(P_{M P C}\right)$

Table 11 Comparison of the results of the individual controllers after welding with an inward groove in the aluminum $\left(n=800 \mathrm{mim}^{-1}\right.$, $v=450 \mathrm{~mm} \mathrm{mim}^{-1}$ and $F_{a, \text { nom }}=2000 \mathrm{~N}$ )

\begin{tabular}{lllll}
\hline $\begin{array}{l}\text { Groove } \\
\text { depth }\end{array}$ & Controller & $\begin{array}{l}\bar{F}_{a} \\
\text { in N }\end{array}$ & $\begin{array}{l}\sigma \\
\text { in N }\end{array}$ & $\begin{array}{l}\sigma / \bar{F}_{a} \\
\text { in } \%\end{array}$ \\
\hline $0.2 \mathrm{~mm}$ & $P_{\text {Model }}$ & 1991.7 & 123.7 & 6.21 \\
& $P_{\text {MPC }}$ & 1993.2 & 162.7 & 8.16 \\
\multirow{2}{*}{$0.4 \mathrm{~mm}$} & $P_{\text {Model }}$ & 1991.0 & 206.2 & 10.36 \\
& $P_{\text {MPC }}$ & 2002.6 & 237.2 & 11.84 \\
\hline
\end{tabular}

Table 12 Comparison of the results of the individual controllers after welding with different parameter sets (PS) corresponding to Table 6 with $F_{a, \text { nom }}=2000 \mathrm{~N}$

\begin{tabular}{lllll}
\hline Parameter & Controller & $\begin{array}{l}\bar{F}_{a} \\
\text { in N }\end{array}$ & $\begin{array}{l}\sigma \\
\text { in N }\end{array}$ & $\begin{array}{l}\sigma / \bar{F}_{a} \\
\text { in \% }\end{array}$ \\
\hline PS3 & $P_{\text {Model }}$ & 1993.1 & 37.2 & 1.86 \\
& $P_{\text {MPC }}$ & 1998.1 & 32.4 & 1.62 \\
PS5 & $P_{\text {Model }}$ & 1994.1 & 81.1 & 4.07 \\
& $P_{\text {MPC }}$ & 1996.7 & 75.1 & 3.76 \\
\hline
\end{tabular}


Table 13 Comparison of the results of the individual controllers after welding with different parameter sets (PS) corresponding to Table 6 and the material combination of EN AW-6082-T6 and PA6-GF30 with $F_{a, n o m}=2000 \mathrm{~N}$

\begin{tabular}{lllll}
\hline Parameter & Controller & $\begin{array}{l}\bar{F}_{a} \\
\text { in N }\end{array}$ & $\begin{array}{l}\sigma \\
\text { in N }\end{array}$ & $\begin{array}{l}\sigma / \bar{F}_{a} \\
\text { in \% }\end{array}$ \\
\hline PS3 & $P_{\text {Model }}$ & 1984.5 & 33.3 & 1.68 \\
& $P_{\text {MPC }}$ & 2000.3 & 30.1 & 1.51 \\
PS4 & $P_{\text {Model }}$ & 1992.6 & 30.5 & 1.53 \\
& $P_{\text {MPC }}$ & 2008.0 & 36.4 & 1.81 \\
PS5 & $P_{\text {Model }}$ & 1985.9 & 38.5 & 1.94 \\
& $P_{\text {MPC }}$ & 2017.9 & 48.2 & 2.39 \\
\hline
\end{tabular}

presented in this section, tool 2 was used without a profiled face (see Fig. 4c), i.e., with a planar end face. Furthermore, the tilt angle was increased to $2^{\circ}$ to introduce an additional model uncertainty. Subsequently, joining tests were conducted with the rotational speed and the feed rate of parameter settings PS3, PS4, and PS5 to evaluate the stationary accuracy. As described in Sect. 5.1, the first $20 \mathrm{~mm}$ and the last $10 \mathrm{~mm}$ were not taken into account for the calculation of the standard deviation. Table 13 shows the results of the experiments.

Despite these model uncertainties and changes compared to the initial set up, the force could be controlled with minimal deviations. The improvement of the values can be explained by the changed tilt angle. If the tilt angle is increased, the surface rate of the plunging tool shoulder per increment is reduced. This leads to a flatter theoretical force characteristic curve in the transmission behavior. Therefore, the force can be adjusted more precisely and less sensitively [10]. In addition, the hypothesis that the force deviation is reduced at lower feeds can be further confirmed. Differences in the controllers exist concerning the force level. For example, the MPC overloads the force curve while the simple proportional controller falls below the force value.

For the adaptation to the material combination EN AW2024-T3 and PPS-CF, the rotational speed was significantly increased due to the increased melting point of the PPS. In addition, the nominal force $F_{a, n o m}$ was set to $2500 \mathrm{~N}$ to take the higher mechanical properties of the individual joining partners into account. Due to the high carbon fiber reinforcement of the thermoplastic joining partner, an additional high compressive strength was given during the joining, i.e., in the molten state. The process parameters, as well as the evaluation regarding the force mean value and the standard deviation, are given in Table 14.

For the stiffer material combination (EN AW-2024-T3 and PPS-CF), the MPC controller offers more stable values with a lower standard deviation. In addition, a smoother force characteristic curve can be seen as well as lower
Table 14 Test result data for the material combination EN AW2024-T3 and PPS-CF, joined with a rotational speed $n$ of $1500 \mathrm{mim}^{-1}$, a feed rate $v$ of $450 \mathrm{~mm} \mathrm{mim}^{-1}$, a tilt angle $\alpha$ of $2^{\circ}$, a nominal force $F_{\text {a,nom }}$ of $2500 \mathrm{~N}$ and using Tool 2

\begin{tabular}{llll}
\hline Controller & $\begin{array}{l}\bar{F}_{a} \\
\text { in N }\end{array}$ & $\begin{array}{l}\sigma \\
\text { in N }\end{array}$ & $\begin{array}{l}\sigma / \bar{F}_{a} \\
\text { in \% }\end{array}$ \\
\hline$P_{\text {Model }}$ & 2491.4 & 54.9 & 2.20 \\
$P_{M P C}$ & 2509.1 & 32.0 & 1.28 \\
\hline
\end{tabular}

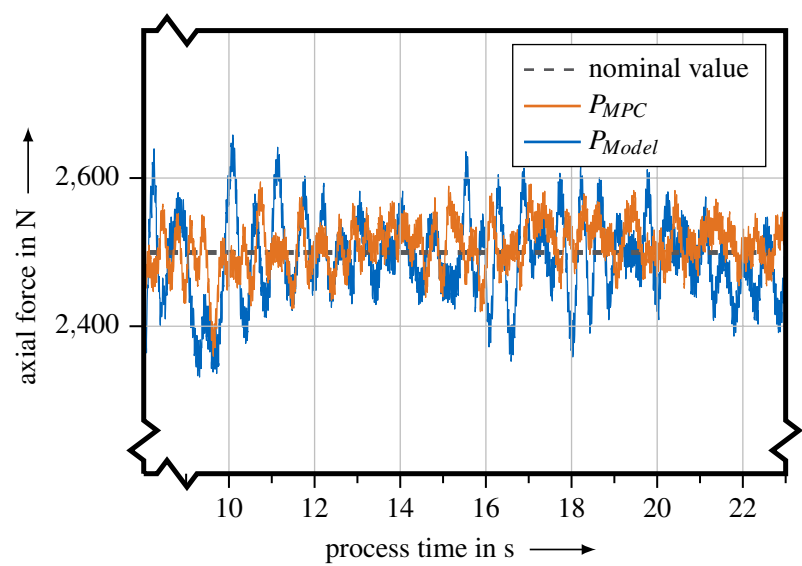

Fig. 14 Comparison of force profiles when joining the material combination EN AW 2024-T3 and PPS-CF $\left(n=1500 \mathrm{mim}^{-1}, \alpha=2^{\circ}\right.$, $v=450 \mathrm{~mm} \mathrm{mim}^{-1}$ and $F_{\text {anom }}=2500 \mathrm{~N}$ )

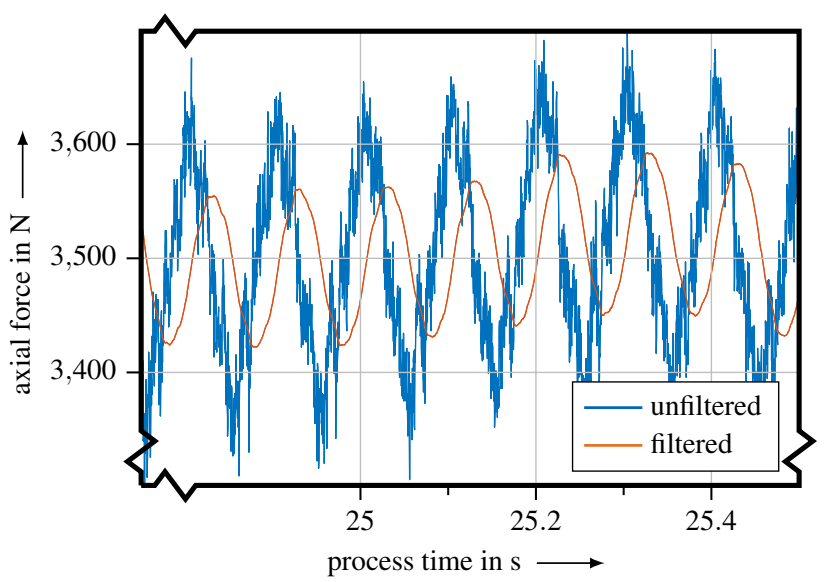

Fig. 15 A comparison of a filtered and an unfiltered force curve using tool 1 at a tilt angle of $\alpha=1^{\circ}$, a rotational speed of $n=600 \mathrm{mim}^{-1}$, and a feed rate of $v=600 \mathrm{~mm} \mathrm{mim}^{-1}$

maximum and minimum peaks of the force (see Fig. 14). As in the previous experiments, it can be observed that the mean force value of the MPC was slightly above the 
nominal value, while the simple proportional controller fell below the mean nominal value.

\subsection{Force signal analysis and adaptation}

The developed closed-loop control system enabled both: a good command response and an effective compensation of disturbances. However, superimposed high-frequency disturbances remained in the signal (see Fig. 15). These components corresponded to the rotational speed of the tool and could be observed in all force signals. In comparison of the two tools used (Tool 1 and Tool 2), the amplitude for tool 1 for parameter setting 4 (PS4) is $85 \mathrm{~N}$, while the profile-less (flat) tool provided only a variation of $30 \mathrm{~N}$. In addition, a dependency of the feed rate on the amplitude was found. The amplitude decreased over the weld seam length up to a steady-state. This steady-state value was dependent on the process parameters and the tool selection. For parameters that introduced more energy (higher number of revolutions per minute to feed rate ratio) into the system and thus led to a softening of the material, a lower force amplitude was measured compared to parameters that introduced less energy. One explanation for this was the reduced stiffness of the joining partners at elevated temperatures. As a result, the axial and radial misalignments of the tool had a lower influence on the force. A measurement of the tools revealed a minimal difference in axial and radial run-out compared to the ideal model, which confirmed the hypothesis.

In order to further investigate this effect, a tool mount was designed to adjust the axial and radial run-out of the tool. As a result, tool 2 could be reduced from an original axial run-out of $0.03 \mathrm{~mm}$ and a concentric run out of 0.04 $\mathrm{mm}$ to $0.01 \mathrm{~mm}$ each, when measuring the tool mounted in the machining center. This adjustment reduced the standard deviation by $38 \%$ when using an MPC controller for a given parameter setting (see Table 15). As a consequence, it can be concluded that the run-out deviation in particular must be considered when designing a tool.

Table 15 Evaluation of the standard deviations and the mean values using the MPC controller with not adjusted and adjusted tool 2 with a rotational speed $n$ of $800 \mathrm{mim}^{-1}$, a feed rate $v$ of $450 \mathrm{~mm} \mathrm{mim}^{-1}$, a tilt angle $\alpha$ of $2^{\circ}$, and a nominal force $F_{a}$ of $2000 \mathrm{~N}$

\begin{tabular}{lllll}
\hline $\begin{array}{l}\text { Axial run-out } \\
\text { in mm }\end{array}$ & $\begin{array}{l}\text { Radial run-out } \\
\text { in mm }\end{array}$ & $\begin{array}{l}\bar{F}_{a} \\
\text { in N }\end{array}$ & $\begin{array}{l}\sigma \\
\text { in N }\end{array}$ & $\begin{array}{l}\sigma / \bar{F}_{a} \\
\text { in \% }\end{array}$ \\
\hline 0.03 & 0.04 & 1991.7 & 87.1 & 4.38 \\
0.01 & 0.01 & 1991.8 & 33.5 & 1.68 \\
\hline
\end{tabular}

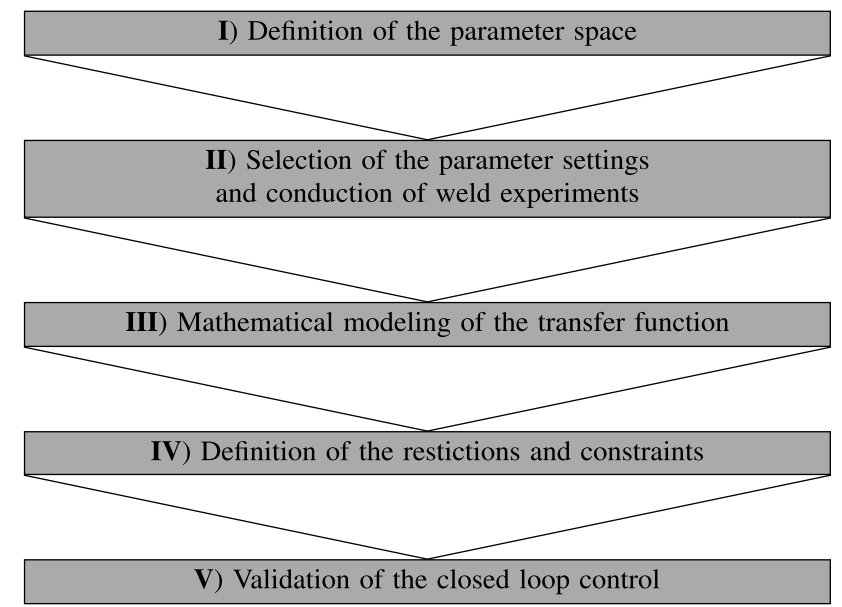

Fig. 16 Method of designing an MPC controller for pressure welding processes

\subsection{Method for designing an MPC controller for friction press joining: retrofit for the user}

In summary, the MPC controller has proven to be advantageous for the FPJ process. However, certain steps must be considered when designing this controller. This section describes a method for the efficient design of this control algorithm for FPJ applications, whereby this procedure can also be used for similar procedures such as FSW (see Fig. 16).

I The first step requires a definition of a parameter space in which the process can be executed. The exact quality of the weld (such as the strength or the optical properties) is of secondary importance, as it has been shown that the MPC also provides reliable control results beyond the original parameter space.

II In the second step, parameter settings are selected that cover a spectrum as large as possible. We propose five parameter sets be used in order to guarantee a statistical certainty, as well as to keep the number of experiments low. For these parameter settings, welding experiments have to be conducted, whereby the manipulated variable (in this example the plunge depth) should be changed stepwise once or twice. The output variable (in this paper $F_{a}$ ) has to be measured.

III The transfer characteristic has to be modeled based on the obtained experimental data. A simple mathematical description of the process in the form of a differential equation system is recommended as an approach for the FPJ process. Generally, other transfer functions are possible.

IV The next step involves the definition of restrictions, i.e., hard and soft constraints (value limits). These 
constrains depend on the system used for the joining process. Afterwards, the required sample time as well as the prediction and control horizon can be determined. The cycle time should be higher than the lowest sample time in the system. The prediction horizon should be chosen to represent the settling time of the system. The control horizon can be set to approximately $30 \%$ of the prediction horizon.

$\mathrm{V}$ Following these definitions, the closed loop control can be set up. Finally, validation tests are to be conducted to test the control loop.

\section{Summary and conclusions}

This study presented a model-based controller design for force control in the FPJ process. Different controller approaches were compared with each other and evaluated regarding their static and dynamic behavior. The most promising controllers were used to investigate the effect of the behavior when encountering model uncertainties. It was found that the model predictive control approach was particularly suitable especially for the transfer to other material combinations. In addition, the run-out of the tool could be identified as a disturbance variable and a suggestion for further improvement could be derived. Altogether, the following main conclusions can be formulated:

C1 A moving average filter is suitable for the pre-filtering of the force signal, if a sufficiently high computing power is available and if the disturbing frequencies are distributed in a Gaussian (AWGN) manner.

C2 Despite a certain self-regulating effect of the process, force-controlled processes are advantageous regarding constant process conditions and a defined nominal force value.

C3 The lower the feed rate $v$, and the higher the tilt angle $\alpha$, the better the force $F_{a}$ can be controlled, which reduces the standard deviation $\sigma$.

C4 A model predictive control approach is the most suitable method to be used when model uncertainties such as material changes, process parameter changes, or tool geometry changes occur.

C5 The imbalance of the tool has a significant influence on the controlled force signal. Therefore it is recommended to minimize run-out when machining tools for FPJ.

Due to the ability of MPC control to handle MIMO systems as well as SISO systems, future research will be conducted on a combined force and temperature control approach. Furthermore, MPC controllers are preferable mainly for non-linear system behavior. However, the controlled system presented in this paper can be described with a linear transfer function with a high accuracy (in the force range considered), whereby the advantage achieved over a simple proportional controller (in combination with the integrating behavior of the axis) is limited. The proposed temperature control is, however, a very non-linear phenomenon, making this combination an excellent suggestion for an MPC control. Here, the developed method can be applied as well. Thereby, an effective implementation of a holistic process control can be achieved.

Acknowledgements Open Access funding provided by Projekt DEAL. This work was funded by the Deutsche Forschungsgemeinschaft (DFG, German Research Foundation)— 418104776.

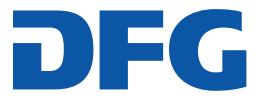

Deutsche Forschungsgemeinschaft German Research Foundation

Open Access This article is licensed under a Creative Commons Attribution 4.0 International License, which permits use, sharing, adaptation, distribution and reproduction in any medium or format, as long as you give appropriate credit to the original author(s) and the source, provide a link to the Creative Commons licence, and indicate if changes were made. The images or other third party material in this article are included in the article's Creative Commons licence, unless indicated otherwise in a credit line to the material. If material is not included in the article's Creative Commons licence and your intended use is not permitted by statutory regulation or exceeds the permitted use, you will need to obtain permission directly from the copyright holder. To view a copy of this licence, visit http://creativecommons.org/licenses/by/4.0/.

\section{References}

1. Altmaier P, Scheuer A, Kretschmer M, Vogt K, Al-Wazir T, Scheurle KD, Richter K, Hofmann J, Behle C (2019) Leipziger Statement: für die Zukunft der Luftfahrt. https://www.bmwi.de/ Redaktion/DE/Pressemitteilungen/2019/20190821-nationale-luftf ahrtkonferenz-2019.html

2. Marsh G (2010) Airbus A350 XWB update. Reinf Plast 54(6):20 24. https://doi.org/10.1016/S0034-3617(10)70212-5

3. Meyer SP, Wunderling C, Zaeh MF (2019) Friction press joining of dissimilar materials: A novel concept to improve the joint strength. In: Proceedings of the 22nd international ESAFORM conference on material forming: ESAFORM 2019, AIP Conference Proceedings. AIP Publishing, pp 050031. https://doi. org/10.1063/1.5112595

4. Meyer SP, Wunderling C, Zaeh MF (2019) Influence of the laserbased surface modification on the bond strength for friction press joining of aluminum and polyethylene. Prod Eng 13(6):721-730. https://doi.org/10.1007/s11740-019-00926-y

5. Wirth FX, Fuchs AN, Rinck P, Zaeh MF (2014) Friction press joining of laser-texturized aluminum with fiber reinforced thermoplastics. Adv Mater Res 966-967:536-545. https://doi. org/10.4028/www.scientific.net/AMR.966-967.536

6. Wirth FX, Zaeh MF, Krutzlinger M, Silvanus J (2014) Analysis of the bonding behavior and joining mechanism during friction 
press joining of aluminum alloys with thermoplastics. Proc CIRP 18:215-220. https://doi.org/10.1016/j.procir.2014.06.134

7. Buffa G, Baffari D, Campanella D, Fratini L (2016) An innovative friction stir welding based technique to produce dissimilar light alloys to thermoplastic matrix composite joints. Proc Manuf 5:319-331. https://doi.org/10.1016/j.promfg.2016.08.028

8. Gebhard P, Zäh MF (2008) Force control design for CNC milling machines for friction stir welding. In: Proceedings of the 7th international symposium on friction stir welding, TWI Ltd

9. Soron M, Kalaykov I (2006) A robot prototype for friction stir welding. In: 2006 IEEE conference on robotics, automation and mechatronics. IEEE, pp 1-5. https://doi.org/10.1109/RAMEC H.2006.252646

10. Longhurst WR, Strauss AM, Cook GE, Cox CD, Hendricks CE, Gibson BT, Dawant YS (2010) Investigation of force-controlled friction stir welding for manufacturing and automation. Proc Institut Mech Eng Part B J Eng Manuf 224(6):937-949. https://doi. org/10.1243/09544054JEM1709

11. Ziegler JG, Nichols NB (1942) Optimum settings for automatic controllers. Trans ASME 64:759-768

12. Zhao X, Kalya P, Landers RG, Krishnamurthy K (2007) Design and implementation of a nonlinear axial force controller for friction stir welding processes. In: 2007 American control conference. IEEE, pp 5553-5558. https://doi.org/10.1109/ACC.2007.4282731

13. Zhao X, Kalya P, Landers RG, Krishnamurthy K (2009) Empirical dynamic modeling of friction stir welding processes. J Mater Process Technol 131(2):021001. https://doi.org/10.1115/1.3075872

14. Oakes T, Landers RG (2009) Design and implementation of a general tracking controller for Friction Stir Welding processes. In: 2009 American control conference. IEEE, pp 5576-5581. https:// doi.org/10.1109/ACC.2009.5160405

15. Fehrenbacher A, Smith CB, Duffie NA, Ferrier NJ, Pfefferkorn FE, Zinn MR (2014) Combined temperature and force control for robotic friction stir welding. J Manuf Sci Eng 136(2):1. https:// doi.org/10.1115/1.4025912

16. Davis TA, Shin YC, Yao B (2010) Observer-based adaptive robust control of friction stir welding axial force. In: 2010 IEEE/ASME international conference on advanced intelligent mechatronics. IEEE, pp 1162-1167. https://doi.org/10.1109/aim.2010.5695824

17. Zhao S, Bi Q, Wang Y (2016) An axial force controller with delay compensation for the friction stir welding process. Int $\mathrm{J}$ Adv Manuf Technol 85(9-12):2623-2683. https://doi.org/10.1007/ s00170-015-8096-9

18. Metzler M, Tavernini D, Sorniotti A, Gruber P (2019) Explicit non-linear model predictive control for vehicle stability control. In: Pfeffer P (ed) 9th international munich chassis symposium 2018, Proceedings, Springer Fachmedien Wiesbaden, Wiesbaden, pp 733-752. https://doi.org/10.1007/978-3-658-22050-1_49

19. de Marchi A, Gerdts M (2019) Free finite horizon LQR: a bilevel perspective and its application to model predictive control. Automatica 100:299-311. https://doi.org/10.1016/j.automatica .2018.11.032

20. Taysom BS, Sorensen CD, Hedengren JD (2017) A comparison of model predictive control and PID temperature control in friction stir welding. J Manuf Processes 29:232-241. https://doi. org/10.1016/j.jmapro.2017.07.015

21. Heckert A, Zaeh MF (2015) Laser surface pre-treatment of aluminum for hybrid joints with glass fiber reinforced thermoplastics. J Laser Appl 27(S2):1938-1387. https://doi.org/10.2351/1.4906380

22. André NM, Goushegir SM, dos Santos JF, Canto LB, AmancioFilho ST (2018) Influence of the interlayer film thickness on the mechanical performance of AA2024-T3/CF-PPS hybrid joints produced by friction spot joining. Welding Int 32(1):1-10. https ://doi.org/10.1080/09507116.2017.1347319
23. Goushegir SM, dos Santos JF, Amancio-Filho ST (2014) Friction spot joining of aluminum AA2024/carbon-fiber reinforced poly(phenylene sulfide) composite single lap joints: microstructure and mechanical performance. Mater Des 54:196-206. https ://doi.org/10.1016/j.matdes.2013.08.034

24. DIN EN 573-3:2018-12, Aluminium and aluminium alloyschemical composition and form of wrought products-part 3: chemical composition and form of products (12.2018). https:// doi.org/10.31030/2870699

25. Kumar B, Widener C, Jahn A, Tweedy B, Cope D, Lee R (2005) Review of the applicability of FSW processing to aircraft applications. In: 46th AIAA/ASME/ASCE/AHS/ASC structures, structural dynamics and materials conference. American Institute of Aeronautics and Astronautics, Reston, Virigina, pp 423. https:// doi.org/10.2514/6.2005-2000

26. Gemmel Metalle \& Co. GmbH (2019) Technical data sheet: AlMgSi1 F30. https://www.gemmel-metalle.de/downloads/Legie rungsbeschreibung_AlMgSi1_F30.pdf

27. Batz+Burgel GmbH \& Co. KG (2019) Data Sheet: EN AW-2024. https://batz-burgel.com/metallhandel/lieferant-aluminium/ en-aw-2024/

28. Otto Fuchs KG (2019) Technical information: material data sheet aluminium. https://www.otto-fuchs.com/en/service/material-infor mation.html

29. S-POLYTEC GmbH (2019) Technical data sheet: PE-HD. https:// www.s-polytec.com/media/attachment/file/d/a/data_sheet_pe-hd_ sheets.pdf

30. Schäfer C, Bryant JS, Osswald TA, Meyer SP (2017) Micropelletization of virgin and reycled thermoplasitc materials. In: Annual technical conference (ANTEC) of the society of plastics engineers (SPE), vol 2017. Society of Plastics Engineers, Anaheim, CA

31. Schäfer C, Meyer SP, Osswald TA (2018) A novel extrusion process for the production of polymer micropellets. Polym Eng Sci 44:1391. https://doi.org/10.1002/pen.24847

32. Kurth M, Eyerer P, Ascherl R, Dittel K, Holz U (1988) An evaluation of retrieved UHMWPE hip joint cups. J Biomater Appl 3(1):33-51. https://doi.org/10.1177/088532828800300102

33. Ensinger Ltd (2019) TECAMID 6 GF30 black—stock shapes. http://www.ensinger-online.com/modules/public/sheet/createshee t.php?SID=707\&FL=0\&FILENAME=TECAMID_6_GF30_ black_0.PDF\&ZOOM=1.2

34. Meyer SP, Jaeger B, Wunderling C, Zaeh MF (2019) Friction stir welding of glass fiber-reinforced polyamide 6: Analysis of the tensile strength and fiber length distribution of friction stir welded PA6-GF30. IOP Conf Ser Mater Sci Eng 480:012013. https://doi. org/10.1088/1757-899X/480/1/012013

35. Wolf M, Kleffel T, Leisen C, Drummer D (2017) Joining of incompatible polymer combinations by form fit using the vibration welding process. Int J Polym Sci 2017:1-8. https://doi. org/10.1155/2017/6809469

36. Amancio-Filho ST, dos Santos JF (2009) Joining of polymers and polymer-metal hybrid structures: recent developments and trends. Polym Eng Sci 49(8):1461-1476. https://doi.org/10.1002/ pen. 21424

37. Lugauer FP, Kandler A, Meyer SP, Wunderling C, Zaeh MF (2019) Induction-based joining of titanium with thermoplastics. Prod Eng 13(3):409-424. https://doi.org/10.1007/s11740-01900888-1

38. TenCate Advanced Composites BV (2019) Data sheet: Cetex tc1100 pps. https://www.toraytac.com/media/221a4fcf-6a4d-49f3837f-9d85c3c34f74/0EEq4g/TenCate\%20Advanced\%20Composit es/Documents/Product\%20datasheets/Thermoplastic/UD\%20tap es, \%20prepregs\%20and\%201aminates/TenCate-Cetex-TC110 0_PPS_PDS.pdf 
39. Akkerman R (2005) Laminate mechanics for balanced woven fabrics. Composites Part B Eng 37(2-3):108-116. https://doi. org/10.1016/j.compositesb.2005.08.004

40. Cole EG, Ferrier NJ, Zinn MR, Duffie NA, Pfefferkorn FE (2012) Forge force reduction via tool design variation. In: Proceedings of the 9th international symposium friction stir welding, 15-17 May 2012, USA. TWI, Cambridge

Publisher's Note Springer Nature remains neutral with regard to jurisdictional claims in published maps and institutional affiliations. 